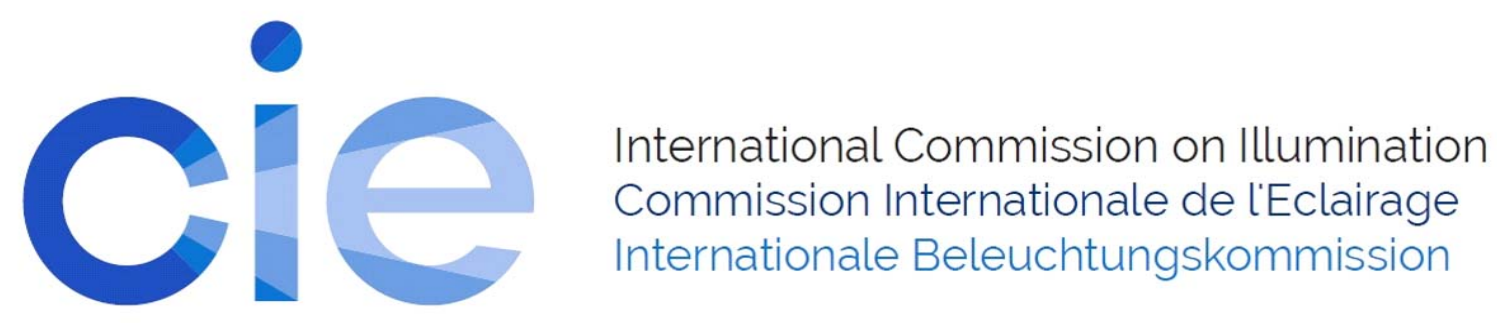

P0179

\title{
VISIBILITY IN SMOKE - EVACUATION LIGHTING IN TUNNELS
}

Pål J Larsen et al.

DOI 10.25039/x46.2019.PO179

from

CIE x046:2019

Proceedings

of the

29th CIE SESSION

Washington D.C., USA, June 14 - 22, 2019

(DOI 10.25039/x46.2019)

The paper has been presented at the 29th CIE Session, Washington D.C., USA, June 14-22, 2019. It has not been peer-reviewed by CIE.

(C) CIE 2019

All rights reserved. Unless otherwise specified, no part of this publication may be reproduced or utilized in any form or by any means, electronic or mechanical, including photocopying and microfilm, without permission in writing from CIE Central Bureau at the address below. Any mention of organizations or products does not imply endorsement by the CIE.

This paper is made available open access for individual use. However, in all other cases all rights are reserved unless explicit permission is sought from and given by the CIE.

CIE Central Bureau

Babenbergerstrasse 9

A-1010 Vienna

Austria

Tel.: +4317143187

e-mail: ciecb@cie.co.at

www.cie.co.at 


\title{
VISIBILITY IN SMOKE - EVACUATION LIGHTING IN TUNNELS
}

\author{
Pål J. Larsen ${ }^{1}$, Arne Jørgensen ${ }^{2}$, Petter Hafdell ${ }^{3}$ \\ ${ }^{1}$ Norconsult AS, Sandvika, NORWAY, ${ }^{2}$ Norwegian Public Road Administration, Oslo, \\ NORWAY, ${ }^{3}$ Swedish Transport Administration, Stockholm, SWEDEN
}

Pal.Johannes.Larsen@Norconsult.com

DOI 10.25039/x46.2019.PO179

\begin{abstract}
The Norwegian and Swedish road authorities, with financial support from Nord FoU, conducted tests for studying evacuation lighting in tunnels and their visibility in smoke conditions. The purpose was to study the general visibility of different lighting solutions and evaluate the appropriate design for evacuation lighting. The test results show that a continuous LED strip mounted on the wall at $1 \mathrm{~m}$ above road surface gives the best illumination for safe evacuation, as measured by contribution to the test subjects' orientation/guidance and feeling of safety. The "spot-luminaires" mounted on the wall at $1 \mathrm{~m}$ above road surface gave almost no contribution to orientation/guidance when placed at $25 \mathrm{~m}$ center-to-center (cc) intervals. Luminaires mounted in the ceiling do not contribute to illumination of the tunnel room shortly after start of a car-fire. Long before the smoke layering reaches the eye-height of observers, the light from the ceiling will have completely disappeared.
\end{abstract}

Keywords: Evacuation lighting, tunnel fire, smoke, visibility

\section{Introduction}

The lighting designs of tunnels, in both existing and new installations, are based on previous practical experience combined with some theoretical studies. Evacuation lighting is chosen from products commercially available on the market. Ongoing technological developments in the lighting industry, however, may provide possibilities which designers of new installations should take advantage of. When retrofitting an existing installation, a cost/benefit evaluation will reveal which actions should be taken.

Lighting technology is developing quite rapidly and creating new possibilities. The relevant national regulations may not keep up with these developments and may not necessarily promote best use of commercially available equipment. At the same time, it is not always true that "more is better" in the world of lighting. This study of currently available evacuation lighting is an important input for ongoing and upcoming revisions of road authority codes.

The Norwegian and Swedish road authorities have close cooperation in the field of lighting in general and have worked on joint standardisation of technical requirements for the Nordic countries. For this study a project proposal for "Nord FoU" funding was prepared and approved. Planning and administration of the project was granted to Norconsult AS under the ongoing project "Lysteknisk kompetanse for Vei- og tunnellys".

\section{Background}

For safe evacuation in smoke, the increased visibility provided by evacuation lighting is very important. Lighting gives guidance, orientation and a general feeling of safety. Historically, evacuation lighting in Norway consisted of single spot luminaires at $1 \mathrm{~m}$ height placed at a maximum $67 \mathrm{~m}$ individual distance. The European regulation was revised some years ago and the maximum individual distance was set to $25 \mathrm{~m}$, with a national exemption note for Norway allowing $33 \mathrm{~m}$ for the rehabilitation of existing tunnels: this allows for the possibility of adding a luminaire in the spacing between existing luminaires. The EN1838 standard referred to in Swedish regulations requires a minimum actual lighting level on the floor:

"For escape routes up to $2 \mathrm{~m}$ in width, the horizontally illuminances on the floor along the centre line of an escape route shall be not less than $1 \mathrm{Ix}$ and the central band consisting of 
not less than half of the width of the route shall be illuminated to a minimum of $50 \%$ of that value".

These installations function as orientation lighting during a power outage or under an early smoke development situation. As an additional aid for guidance, continuous LED-strips in a longitudinal orientation along the tunnel are now commercially available. When such new products are introduced, the requirements are determined more by the capacity of the technology and some application of previous best-practice experience. The need for a more evidence-based study of the actual requirements and consequences in a real environment was voiced by the legislative authorities. With this background, an initiative was launched by the Swedish and Norwegian road authorities and Nord FoU founding was granted.

\section{Location and Measurement setup}

\subsection{Location}

The test was held at "IF forsikring skadesenter" in Hobøl Østfold county in Norway. A 100 m long tunnel, T 9,5 m profile, was used for testing, without normal traffic. At both sides of the tunnel (seen in longitudinal direction) there was a heightened concrete boardwalk, approx. 20 $\mathrm{cm}$ above the level of the roadway in the tunnel. All measurements of mounting height are referenced to the roadway of the tunnel. Before our test the walls of the tunnel were painted white between 0-3 m height.

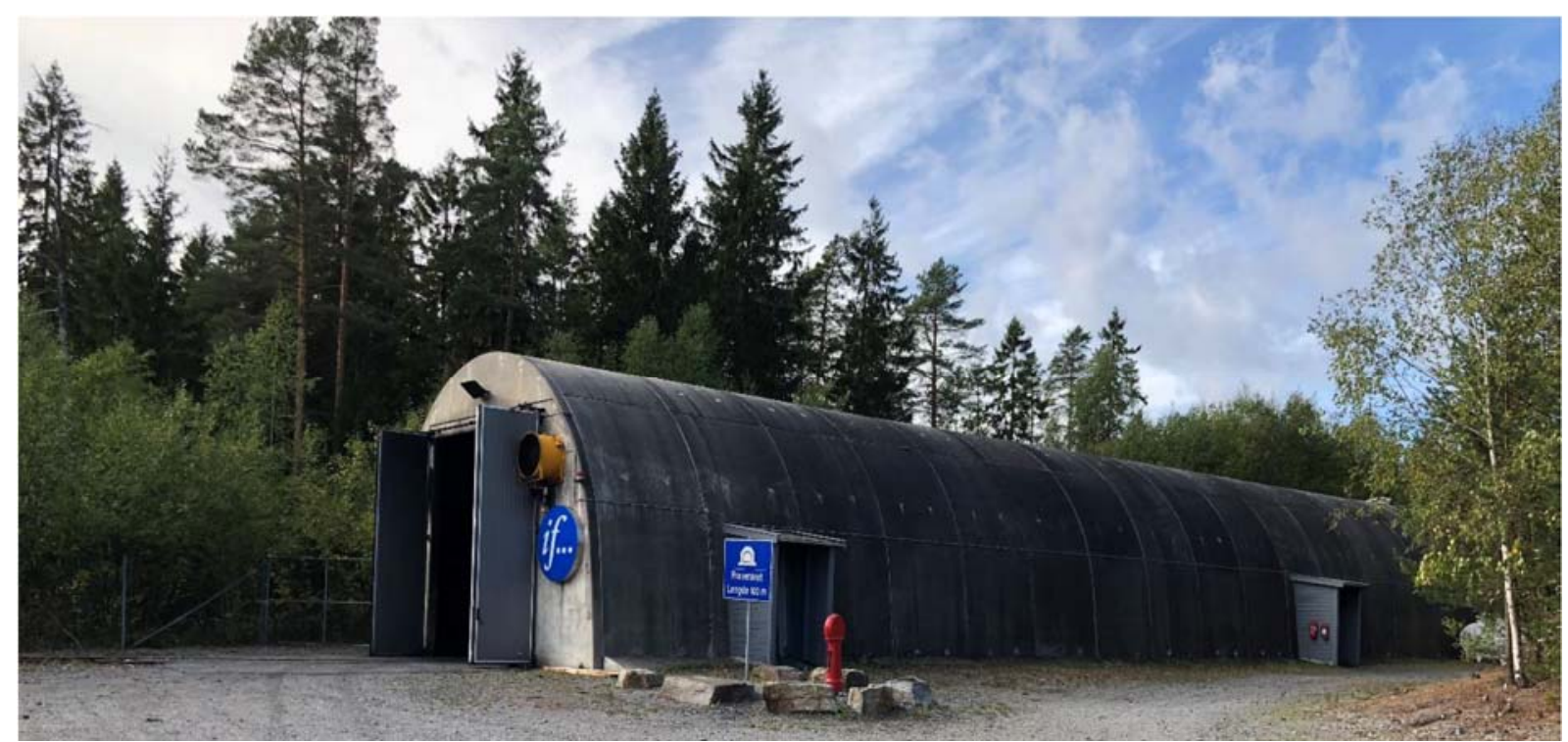

Figure 1 - Image of test tunnel

\subsection{Measurement setup}

Visibility as experienced by humans is a subjective matter; everyone has their own experience of how linting relates to their feeling of safety. Feedback from individuals on visibility, especially in a stressed situation in fire/smoke, will have a subjective component. In this experiment such feedback was recorded as an important part of the result. In addition, the objective measures of visibility were collected through metering of illuminance from all lighting fixtures at $1 \mathrm{~m}$ distance throughout the experiment's timeline. Also, each illuminance meter was supplemented with a video camera for continuous feed/documentation on the visibility conditions. 


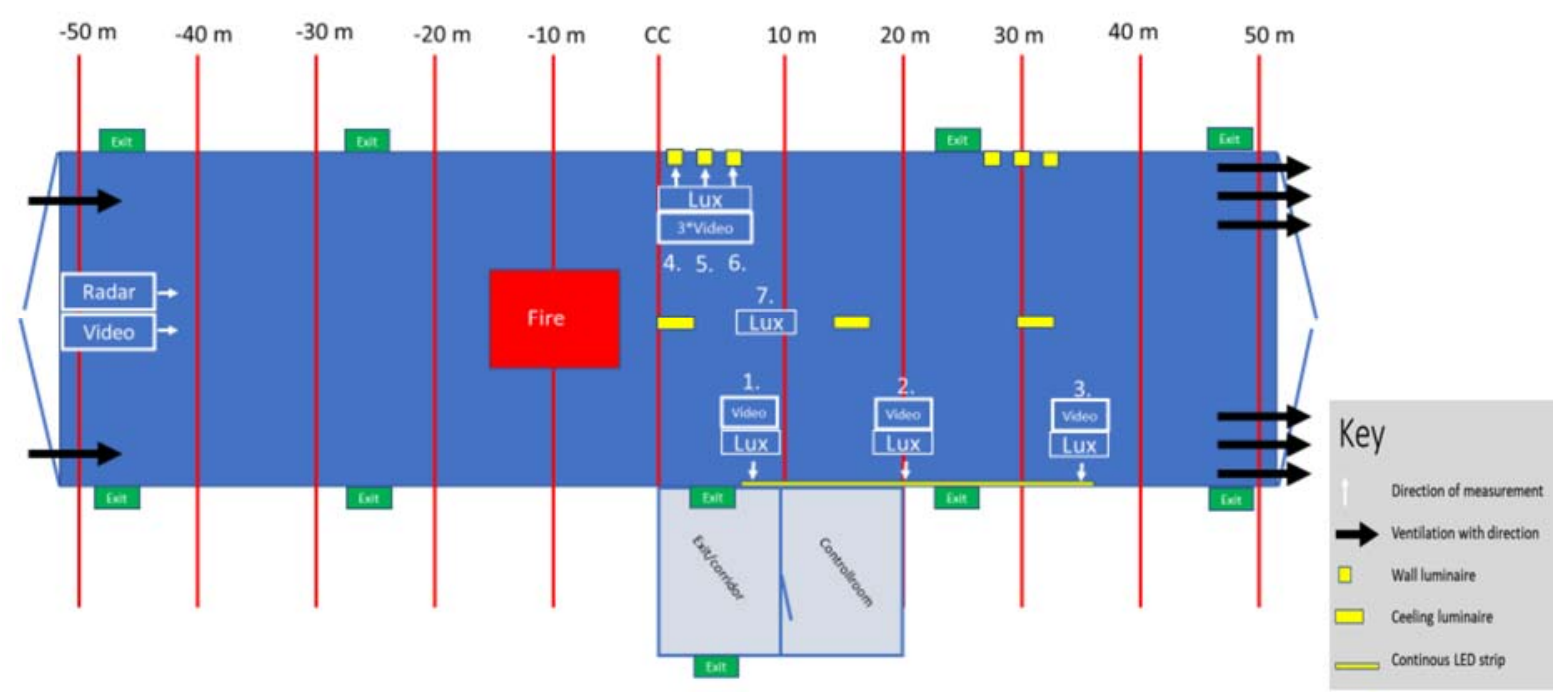

Figure 2 - General experiment setup

\section{Results}

By mistake all illuminance sensors were delivered calibrated for [0-20.000] instead of [0-2000] lux. Therefore, the loggings presented here must be interpreted only as relative indications. Small interference and noise levels on the transmitting cable will also have a large influence on the measurements. It is also worth noticing that the sudden drops to 0 in the loggings may be caused by test persons standing/walking between instrument and light source

\subsection{Setup 1}

The intent of the setup was to achieve "worst conditions" with a dense dark smoke, simulating no ventilation. LED strip was set to $50 \%$ setting giving approx. 200 lumens per meter, and the EnergyOptimal point source was also set to $50 \%$.

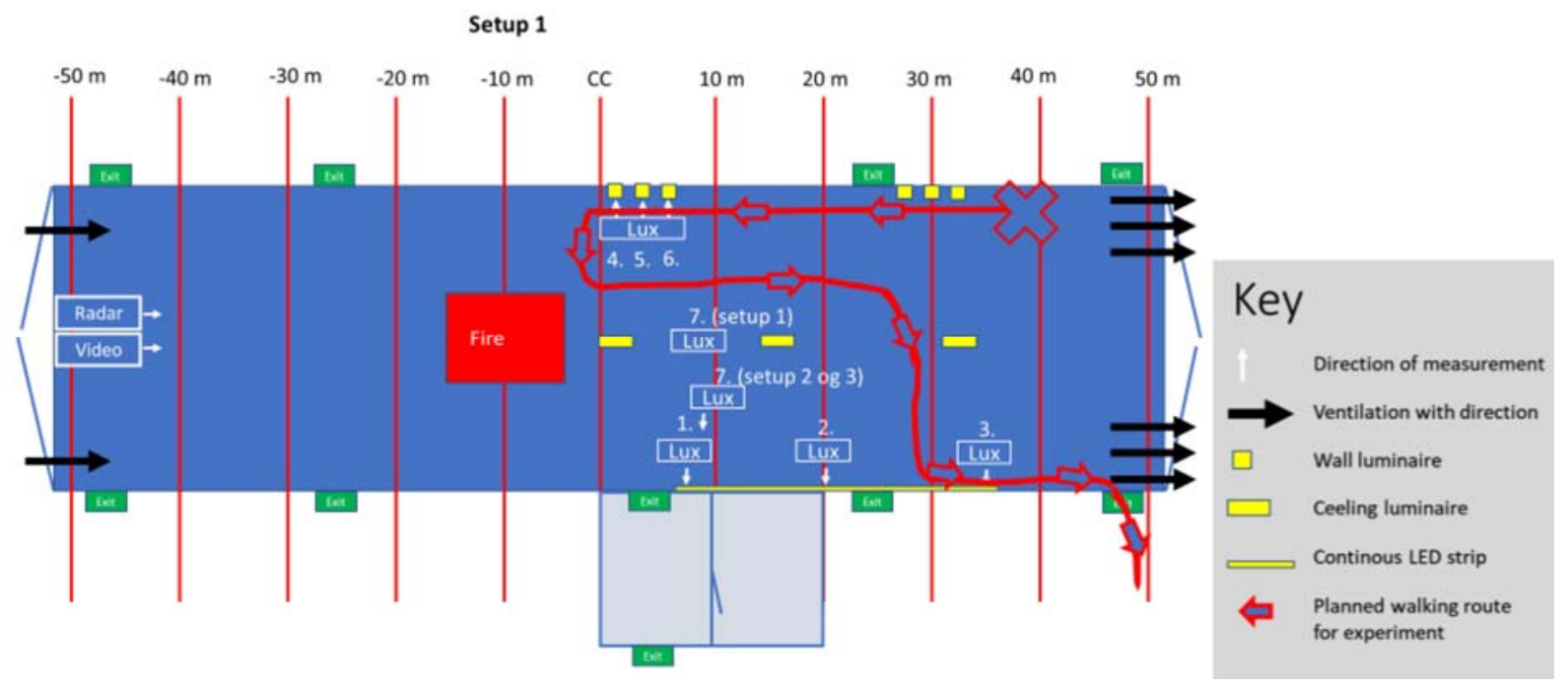

Figure 3 - Setup test 1

\subsubsection{Debrief experiences}

\section{Observers:}

Worst conditions were achieved in the test tunnel. This was the first time in real smoke for most of the test persons and the experience of complete darkness may have had a psychological 
influence on the evaluation results. Test persons reported a maximum of $1 \mathrm{~m}$ visibility distance to every evacuation light source included. This was the same for the LED-strip, but $1 \mathrm{~m}$ visibility was sufficient for good orientation and guidance to allow quick evacuation. Previous experiments with artificial smoke show that lights illuminate the smoke, thus contributing to both visibility and orientation. Real smoke, on the other hand, gives a near total blackout. The ceiling luminaires were quickly completely darkened from the start of the experiment, before the smoke lowered towards eye height, the smoke in the top layer causing a complete blockage of light from the luminaries mounted at $4 \mathrm{~m}$.

\section{Firemen:}

Conditions with closed tunnel end-doors caused an under-ventilated fire with limited available oxygen content in the air (Norwegian: "sur brann"). These conditions simulate a long tunnel with high gradient and a cloud where the smoke meets cold air. The layering of the smoke was below approximately. $0,5 \mathrm{~m}$, representing worst possible conditions.

\subsection{Setup 2}

Fire and smoke conditions were similar to the first setup, but ventilation was not activated after fire was out; only the doors at the end were opened. Different levels of light output and its influence on visibility distance and contribution to orientation/guidance were noted/registered.

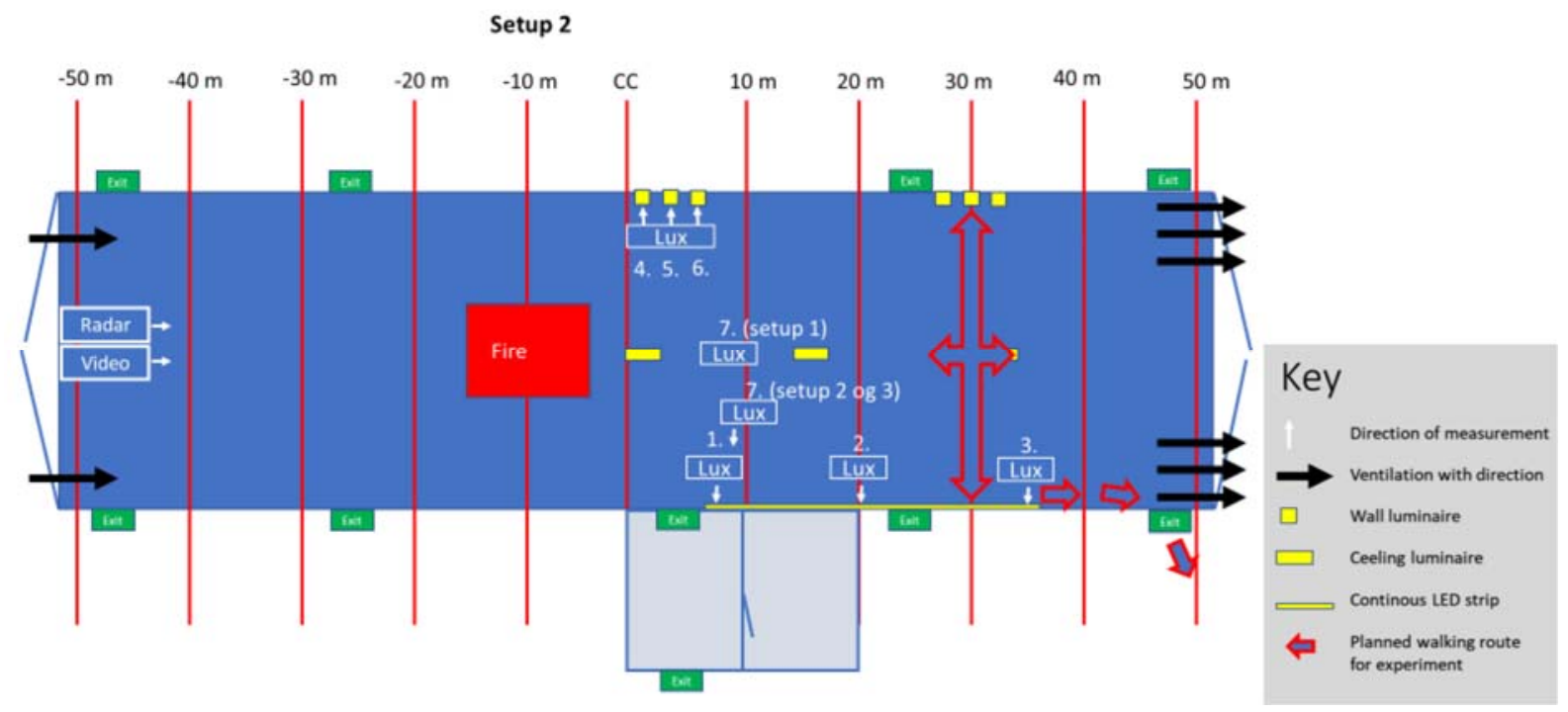

Figure 4 - Setup test 2

\subsubsection{Debrief experiences}

\section{Observers:}

Trials at different levels were performed. The observers experience showed that going from approximate 10-50-100 \% level gave little difference to what distance the lights were visible. Some test persons reported slightly longer visibility distance with more output, while some reported no difference at all. Regarding situational comfort, the $10 \%$ level was reported to give sufficient guidance (when first seen), while the increase to $50 \%$ and $100 \%$ levels did not give any practical increase in evacuation speed.

\section{Fireman:}

Lower level gave better visibility as the smoke is less lit up, making it easier to see a leading line at the lower lighting level. The higher light levels create increased capsular effect in the smoke, and more glare 


\subsection{Setup 3}

Dense smoke developed approximately 5 minutes before ventilation was turned on ( 2 fans blowing in and 2 blowing out). The LED strip and Morrem guidance light were set to $50 \%$ dimmed, Markled and Trafficled were set to $100 \%$ output. At end of the experiment the firemen start to extinguish the fire with water, and observe the impact on visibility.

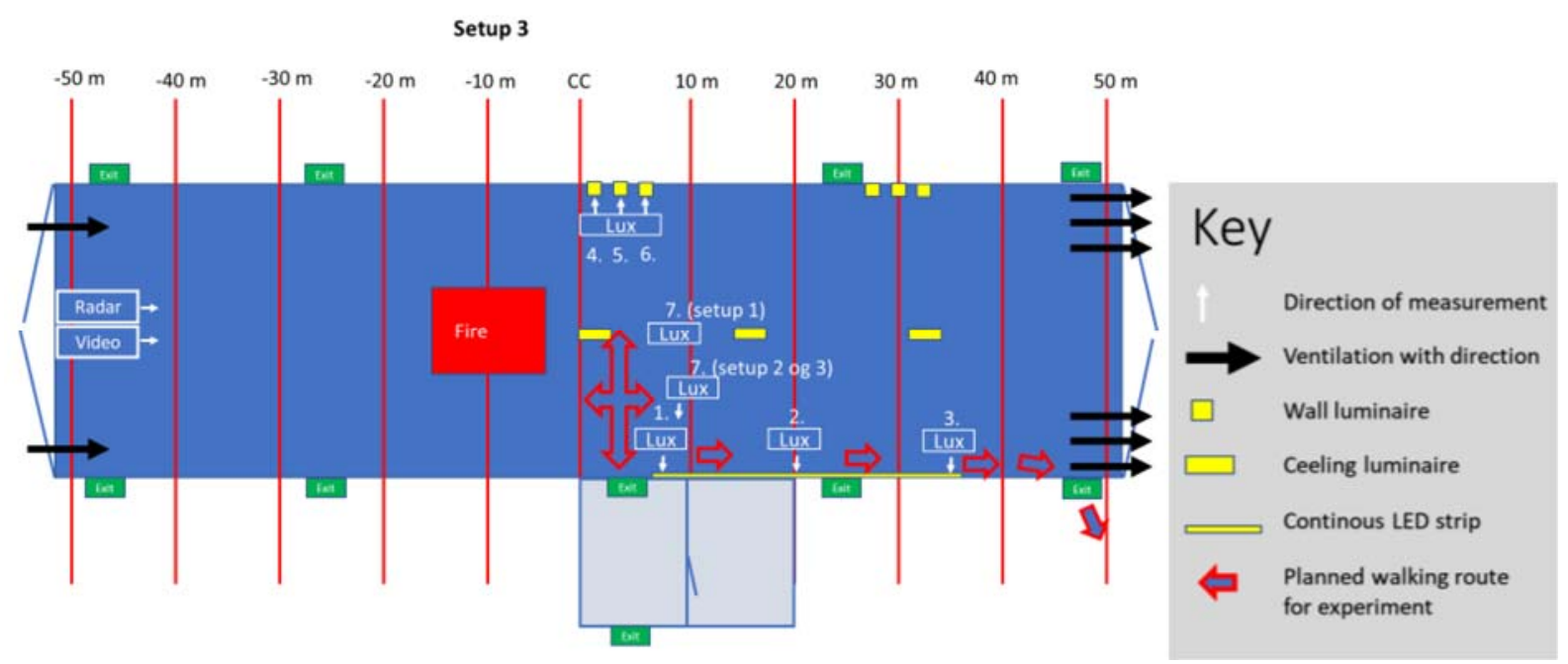

Figure 5 - Setup test 3

\subsubsection{Debrief experiences}

In ventilated smoke the experience was approximately $15 \mathrm{~m}$ visibility distance, giving good orientation from opposite side of tunnel (wall to wall). In these conditions the evacuation lights were almost too bright. But experience from opposite side, looking backwards to the far end while walking towards exit, still showed complete darkness with no visibility.

When water was added the "lit smoke" experience was more visible. The luminaires whose optics send light downward were experienced as being more comfortable than the optics sending light in every direction. The single luminaire evacuation light giving a continuous high light level with some glare might have the effect of slowing down when passing the luminaire giving a longer evacuation time.

\section{Discussion}

\subsection{Test 1}

The worst conditions with a "total black-out" confirmed the hypothesis that normal lighting located on the ceiling disappears a long time before the smoke becomes a problem at ground level. Also, visible distance to all lighting was observed to be below $1 \mathrm{~m}$. The design requirements stating "1 lux on the floor" or a maximum separation distance of $25 \mathrm{~m}$ experience would, in our tests, have provided little to no practical guidance. Luminaires were visible just as the observers passed them, but provided no overall direction, orientation or visible effect on the escape route. On the other hand, the LED strip, after first being seen, gave people a clear orientation and direction of escape. It also gave a subjective feeling of safety as it indicated a "feeling of room", not just a single disconnected spot of light.

\subsection{Test 2}

By creating worst-case conditions, this experiment gave a good test of measured and experienced lighting levels. Moving from $10 \%-50 \%-100 \%$ level showed that in a total smoke blackout an increase of luminous flux not necessarily lead to an improved practical effect. Results showed that the visible distance did not increase linearly as output was increased. Rather, results showed a tendency toward increased output from luminaires causing only more glare. For the LED-strip this result might be a relevant issue. The $50 \%$ level, representing 200 $\mathrm{Im} / \mathrm{m}$ seems like a good design solution. Higher flux did not increase the visible distance, the 
effect resulted just in more lighted smoke. This lighted smoke made it more difficult to see the line along the wall, which was the feature which had the most positive contribution towards orientation/guidance.

For the single luminaire this linear guidance effect is not present regardless of lighting level, so the motivation for keeping the flux low might not be as relevant. The experience of the observers indicated that levels above $50 \%$ (approximate $200 \mathrm{Im} / \mathrm{m}$ for continuous LED strip) gave no significant positive increase on the visibility or orientation.

\subsection{Test 3}

Test conditions simulating a more "normal fire" with tunnel ventilation showed a longer visibility distance for the evacuation lighting. And yet, the 6-10 $\mathrm{m}$ visibility distance shows that single luminaires placed at $25 \mathrm{~m}$ intervals distance give poor orientation and guidance for the persons evacuating. To have an effect this distance should be decreased to maximum $10 \mathrm{~m}$. At the same time, one must consider our test used a $5 \mathrm{MW}$ fire; in the case of a larger fire the ventilation might not give the same effect and our "worst case" scenario might be more representative. Under worst-case conditions even a $2 \mathrm{~m}$ cc distance would give poor guidance.

In addition, a single luminaire does not provide any information about orientation relative to the room. The experience of the continuous LED-strip, however, provides a good experience of the tunnel room so that the time spent on evacuation decreases. A compromise solution would be single luminaires which are physically extended in the longitudinal direction (not only by optical illusion) of the tunnel by a length of $1 \mathrm{~m}$. A requirement for $1 \mathrm{~m}$-long LED strips every $5 \mathrm{~m}$ for increased orientation might improve the effect. A luminaire with increased physical size in longitudinal direction would be more easily detected.

Further investigation of real-time escape performance under realistic smoke from a larger potential fire source, such as simulating a truck fire, should be done to give more accurate advice. Different mounting heights, lower than $1 \mathrm{~m}$, were not investigated and might have an impact. Mounting lights at such a low height may, however, cause increased maintenance issues.

\subsection{Outcome}

The main purpose of our testing was to investigate different types of evacuation lighting and evaluate their contribution to guidance, orientation and general feeling of safety. One finding that is obvious is that the type and density of smoke has a direct influence on all these factors. An interesting observation is that increased lighting, which might have given a better feeling of safety under normal conditions, was not helpful to either guidance, orientation or the feeling of safety in our setup. Single luminaires give no orientation or guidance if one cannot see the next luminaire, and the wall surface cannot be used for direction either as it is hidden behind thick smoke. If the single luminaires could be physically stretched out in the longitudinal direction then they would give more contribution to guidance/orientation, even if only a single luminaire is seen.

As the layers of smoke rose and accumulated under the ceiling, the high-mounted luminaires for general lighting quickly lost their function and gave no light towards the floor, becoming useless in this setting.

The tests were done only with cars and all 3 experimental setups had similar fire-effect, approximate $5 \mathrm{MW}$. There is a chance that a larger fire-effect and/or longer tunnel would create a different layering of the smoke and thereby different outcomes.

The subjects in these tests were not a random selection from the general population. All persons were either firemen or had knowledge of evacuation lighting and were instructed beforehand on the hypothesis and plan for experiment. Using test subjects without previous knowledge or instructions might have given other feedback. 


\section{Conclusions}

Contribution from luminaires in the ceiling can be neglected in an escape situation.

Single luminaires at $1 \mathrm{~m}$ height with a $25 \mathrm{~m}$ cc distance give no help in smoke conditions. In the case of a ventilated car fire a decrease to $10 \mathrm{~m}$ cc distance is necessary to give any practical guidance effect. Under worst-case conditions the single luminaires give little to no contribution at all.

Continuous LED strips provide good orientation and guidance along the wall. $200 \mathrm{Im} / \mathrm{m}$ is sufficient for the visible effects needed in an escape situation in smoke. In thick smoke no light will reach the floor no matter how high the installed lumen intensity $(\mathrm{Im} / \mathrm{m})$.

Future investigation of the different effects induced by a larger fire, for example from a truck fire, will enrich the present findings. 